\title{
An African American Man in Police Procedural Drama: Black Masculinity Representation on Criminal Minds
}

\author{
Sarah Khansa Agharid ${ }^{1}$, Muhammad Fuad ${ }^{2}$ \\ \{khansagharid@gmail.com ${ }^{1}$, faseha.fuad994@gmail.com² $\}$ \\ ${ }^{1,2}$ American Studies, School of Strategic and Global Studies, Universitas Indonesia, Jakarta, Indonesia
}

\begin{abstract}
This paper analyses how black masculinity is portrayed, constructed, and performed in a police procedural drama scenario through the character of Derek Morgan in Criminal Minds. The representation of African Americans in this genre is mostly negative. The paper aims to see how the portrayal of Derek Morgan is empowering or stereotyping the representation of black masculinity. Related scenes and dialogues were analyzed using Eder's clock of character analysis. To some extent, as the only black officer in the team, Derek's representation is opposite to the typical characteristic of stereotype typically attributed to African American males. Derek is a loving, determined, committed, benevolent, and daring black man. However, this representation of reconstructed black masculinity is perhaps only possible on a television series within the context of police procedural drama as a law enforcer.
\end{abstract}

Keywords: African American men, black masculinity, police procedural drama, Criminal Minds.

\section{Introduction}

Television is one of the media used to entertain people when they are at home. Television creates a space where we can hear stories we have never heard in everyday life. The problem of representation on TV can be one of the issues that are always discussed when the fictional space on television interpreted to the real world. Marginalized groups usually get affected by their representation on TV, and one of them is the African American group. The limited representation of African Americans on television consists mainly of characters carried out in ways that uphold stereotypes that address the African American community and culture.

Reality shows, talk shows, news, and TV series are some types of shows that are broadcasted on television. TV series is a television program that presents serial stories whose stories can be taken from real life or just mere fiction. Since the 1990s, TV series that centred on stories about law enforcement began to emerge like Law and Order and CSI. Criminal Minds is one of the TV series which is included in the police procedural drama genre. The series debuted in 2005 and is still airing with a total of 14 seasons now. The series is renewed for its $15^{\text {th }}$ season, which will be the final season of the series ending in 2020. "The series revolves around an elite team of Federal Bureau of Investigation (FBI) profilers who analyse the country's most twisted criminals, anticipating their next moves before they strike again" [1]. Most of the original main characters in this series are whites; only one of them is African American. That character is Supervisory Special Agent Derek Morgan, portrayed by African American actor 
Shemar Moore. The police procedural drama narrative not only presents how the team works to investigate and solve criminal cases but also how the team members live their life with professional and personal problems. The character Derek Morgan proposes a representation of black masculinity rarely seen before on television, which partly allowed by the focus of this series on social, racial, and gender relations in a law enforcement scenario.

Since it's released, Criminal Minds has been analysed by critics and academicians. Many people studied the series from the perspective of law enforcement. Legros [2], in her research, discusses the series' depiction of criminal profiling by questioning whether it is a reality or only a fiction. From two episodes of Criminal Minds that were analysed, Legros [2] concludes that the criminal profiling showed in the series "despite a few exceptions, adhere to legitimate reallife criminal profiling considerations and practices" and "[the series] may not be fictional as its dramatic category may lead viewers to believe." Another academician, Levin [3], studies the representation of victims, suspects, and perpetrators in four TV series with the crime action genre, namely Law and Order: Special Victims Units, Criminal Minds, Body of Proof, and Rizzoli \& Isles. Levin's study results show that "there is a very narrow lens in regard to the victims, suspects, and perpetrators portrayed on television. It is very important to widen the lens through which television and other media portray victims, suspects and perpetrators, as it can be dangerous to have such a narrow view."

However, little has been done to analyse the characters from this series, especially when there is only one African American man as a representation of black masculinity. Black masculinity itself has been widely investigated in popular culture by researchers. Castle Bell and Harris [4] examines the representation of black masculinity on TV series entitled Parenthood through the black man character, Alex. Through Alex, black males are depicted as being social failures, criminals, violent, and hypersexual [4]. Another scholar, Tyree, Byerly, and Hamilton [5] study the representation of black masculinity in news stories. Tyree et al. [5] discover "the majority of the stories - slightly more than half - met the Post's goal of representing Black men in 'uncommon ways' - what this research conceptualized as a counterstereotype." [5, p.477]. They also state "the (news) series offered a strong example of how Black masculinity can be exhibited in news media text, and, ... can advance representations of Black men with representations of Black masculinity..." [5, p.479].

Criminal Minds offers a unique performance of black masculinity rarely seen on television through Derek Morgan's character. Not many researches have been conducted to analyze how black males are presented in the context of shows dominated by white, especially with a white male as the lead character. The focus of this paper is how black masculinity is portrayed, constructed, and performed through Derek Morgan's character and how these images are empowering or stereotyping the representation of black men. Focusing on the narratives of black masculinity in Criminal Minds, I argue that to some extent, Derek's character and representation as the only black officer in the team are opposite to the common characteristic of stereotype typically attributed to African American males. The narratives from selected episodes that centered on Derek Morgan suggest several readings and interpretation; first, Derek's position as a valued member of the team is due to the reconstructed black masculinity attributes of being benevolent patriarch, determined, daring, and loving man; and second, Derek's evolution into a representation of reconstructed black masculinity is perhaps only possible on a television series within the context of police procedural drama as law enforcer. 


\section{Theoretical Framework}

\subsection{Understanding Police Procedural Drama}

Since the end of the Second World War, the American television industry has presented viewers with lots of television shows with the detective genre. Socio, political, and cultural conditions changes occurring in America influenced and shaped the detective genres. According to Primasita and Ahimsa-Putra [6], police procedural drama is a subgenre of the detective genre that flourished in the mid-20th century. To some extent, police procedural is distinct from the detective genre, yet having similarities in the essential elements such as plots, motifs, character, setting, theme, and props [6]. The most noticeable difference is it involves a division or department from law enforcement institutions (e.g., FBI, LAPD, NYPD). As it focuses on law enforcement institution, there are procedures and bureaucracy that must be followed; all characters are part of a team, so they have to work together to solve the crime; and usually, the cases carried out by the team and their work as police officers affect their personal lives in the storyline. However, police procedural drama follows the narrative structure just like detective genre; at the beginning, the victim is involved in a mysterious event, the dead victim is discovered, investigation process, the false perpetrator is caught, re-investigating, and finally the real perpetrator is arrested [7].

Police procedural drama offers a distinctive spectacle where race, gender, and class relation come into play. Many studies have researched the socio-cultural discourse of this genre. At the onset, detective genre like this uses male as the lead detective character, then uses female as the lead detective character as a result of social changes; the emergence of women's movements and discourse of equality (Mizejewski as cited in [6]). However, when CSI: Crime Scene Investigation first aired in 2000, the male lead character became a phenomenon again that being followed by other shows [8]. Since police procedural drama is typically dominated by male characters and therefore depicts masculinity, Scharrer [9] analysed the portrayals of masculinity in this genre from time to time, specifically tv series from the $50 \mathrm{~s}$ to $90 \mathrm{~s}$. The study showed that "the police and detective genre shows a shift toward a "new" or "conflicted" masculinity that combines traditional roles with more progressive ones in depictions of male characters [9, p.105]." Likewise, Creeber [10] examined how the portrayal of masculinity changes in a British tv series entitled Cracker (1993-1996). The study revealed that the male lead character depicts the new form of masculinity, which called the new lad. "The term has been used to symbolize a new breed of men who have apparently 'reconstructed' masculinity in the face of its continual criticism [10, p.182]."

Apart from gender discourse, this genre can also be seen from race discourse. Furthermore, Jenner [8] mentions, "particularly discourses of race are understood here as significantly shaping American history in ways that highly influence detective dramas, meaning that it is never completely ignored [8, p.11]." In her findings, Scharrer [9] also notes that "characters of colour are vastly underrepresented." In the gender studies, males are understudied, which makes the studies on black males on police procedural is scant. Mostly in talks on sport and music genre. Aside from the studies that examined masculinity in police procedural drama, little has been done to examine black masculinity in the genre.

Minorities such as African Americans are likely to get over or underrepresented in the film or television. For example, Dixon \& Linz [11] studied the representation of minorities (Blacks and Latinos) on television news. Their results show that Black people and Latinos are more often depicted as perpetrators and lawbreakers compared to white people. Moreover, they reveal that the portrayal of black people as perpetrators are overrepresented, while the portrayal of 
black people as a police officer is "neither over- nor underrepresented" on television news [11]. Another study by Dixon \& Azocar [12] conducted a study on the portrayal of juvenile perpetrators based on race on television news. They find out that on television news, young Black and Latinos are more likely to be represented as perpetrators compared to whites. They also state that the portrayal of young black people as perpetrators are overrepresented on television news.

\subsection{Understanding Black Masculinity}

Masculinity is the characteristic attached to men defined by the traditional patriarchal society, what does it mean to be a man. To be a man means you are expected to be strong, powerful, tough, aggressive, dominating women and others. If you are a man and fail to have those kinds of attributes, the society will not see you as a manly man. Then, there is black masculinity. Black masculinity is a term used to describe the social attributes attached to African American men. African American men in America lost their identity. As men, they are not accepted in the white men's group. As African descent, they lack knowledge about their roots. As long as they live in America, especially from the slavery era, their masculinity and identity have been defined by the stereotype structured by the dominant group, which is white culture. In the $19^{\text {th }}$ century, black males were seen as animals, brutes, natural born rapists, and murderers. They were also lazy and shiftless. All they did were only drinking and having fun. They were described as untamed, uncivilized, unthinking, and unfeeling.

However, the characteristics of black masculinity have changed throughout American history. Bell Hooks is one of the scholars who try to reconstruct the definition of black masculinity. Hooks [13] explains that stereotypes of black masculinity, such as black men are failures, dangerous, violent, criminals, hypersexual, rebel, cowards, emasculated, playboy, and unfaithful, can be traced back to historical narratives since slavery up to now. She argues that all the negative stereotypes of black masculinity are from white's perspective, how white people look at black men, and it depends on the view of white patriarchal masculinity. In her writings, Hooks reconstructs black masculinity through black people's point of view.

In "We Real Cool: Black Men and Masculinity", Hooks [14] said that black men have a different idea about masculinity from white men. For example, white men define masculinity as to dominate others and women. This attribute of dominance the white men think as a masculine trait was shown in their mission to colonize others. While historically, the sense of masculinity of black men is not defined by the will to dominate others and women. Dominance and violence that black men were stereotyped as a result of slavery. Black men were taught by their white masters about white patriarchal masculinity. "They had to be taught that it was acceptable to use violence to establish patriarchal power" [14, p.2]. However, Hooks [14] also discovers "enslaved black males were socialized by white folks to believe that they should endeavour to become patriarchs by seeking to attain the freedom to provide and protect for black women, to be benevolent patriarchs" [14, p.3]. Unfortunately, not all black men agree with this benevolent patriarch. Some of them continue using violence to dominate and accept the white patriarchal masculinity while some of them resist.

Another example is that black men are emasculated. In this sense, black men are emasculated in terms of economics [14]. It is because more black women are working and earning money rather than black men. In white patriarchal masculinity, men should be the breadwinner, not women. So, when black women become the breadwinner and earning more money than their husbands, white men pointing out that black women have emasculated black men, and black men are not strong patriarchs. This notion makes the implication that black men 
blame black women for their situation and become women-haters. Even though black women are the one who works and earn money, but the one who controls the money in the household is their husbands, the black men. "Not all black families cared about black women earning more as long as black males controlled their earnings" [14, p.9]. It can be said that in this sense of black masculinity is black men do not feel they are emasculated and still have power.

From Hooks' writings, it can be said that there are conventional black masculinity and unconventional black masculinity. Conventional black masculinity is the attributes typically associated with black men set by the white culture, which include mostly negative stereotypes of black men and the most dangerous and feared forms of patriarchal masculinity. Unconventional black masculinity is the attributes of black men that Hooks reconstructs through the historical perspective of black people.

\section{Research Method}

The method used in this research is character analysis by Jens Eder called the clock of character. The clock of character is one method to analyze characters from the film. From Figure 1 below, there are four aspects to understand characters in a film using the clock of character, we can analyze the characters as 1) artifact; 2) Fictional being; 3) Symbol; and 4) Symptom [15].

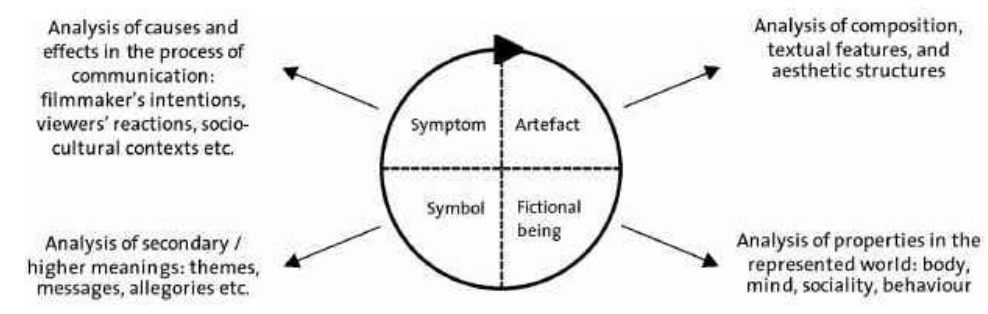

Fig. 1. The clock of character [15].

Analysing characters as artifact means that we explain "how and by what means the character is represented" in the film [15, p.21]. We use information from outside the character to understand him/her, such as music, properties, lighting, camera angle, and character's position which contributes to characterization. Analysing characters as fictional being means that we analyse "what features and relations the character possesses as an inhabitant of a fictional world, and how the character act and behave in this world" [15, p.21]. In other words, it can be said that the analysis will be looking at some aspects of characterization such as appearance, personality traits, actions, words, and motivation. As a symbol, we analyse the character to find out "what the character stands for and what indirect meanings/hidden messages the character conveys" [15, p.21]. As symptoms, the characters are analysed to discover "what causes the character to be as it is, and what effects it produces to audience" [15, p.22].

Eder also notes that in analyzing the characters by using this approach, we do not always have to follow all the aspects. "When viewing and analyzing films, the attention may move among those four aspects and eventually become focused on one or more of them" $[15, \mathrm{p} .22]$. 
Therefore, this research will be focused on analyzing Derek Morgan as a fictional being and symbol. The data used are some related scenes and dialogues which contribute significantly to the portrayal of black masculinity in Derek Morgan's character.

\section{Result and Discussion}

Derek Morgan is a Supervisory Special Agent (SSA) at the Behavioral Analysis Unit (BAU) FBI. Prior to joining with the BAU, he had experienced as a police officer at Chicago Police. His expertise is on obsessional crimes and explosives. As known in popular culture, the depiction of a black man as a federal agent is rare. Mostly, black men are depicted as failures or criminals. Even if they got roles as police, it is usually only as a partner. Hooks [14] states that black men did not have a chance to get an excellent respectable position in mainstream jobs. It can be inferred that by depicting Derek as a federal agent, it shows that there is a progressive representation of black men on the television.

From his appearance, Derek is physically strong, fit, and active. He is depicted as the muscle of the team. He has an athletic body and always be the one who kicks the door and uses physical strength to catch the suspects. The depiction of a muscular black man is a stereotype that reinforces the aggressiveness of black masculinity. It also suggests that black males are "being more body than mind" [14]. Although Derek always participates in the discussions and gives opinions and solutions to solve the cases, the physically strong portrayal of Derek is more highlighted. Inversely proportional to the description of one of his co-workers, Dr. Spencer Reid (a white male), who is described as smarter and uses his brain more often than his physical strength.

Other male characters, whites, wear formal attire like a shirt and suit while Derek dresses casual wear. Derek wears a t-shirt, a leather jacket, and jeans. This wearing signifies different kinds of masculinity. "The suit is often understood as emblematic of dominant masculine ideals" [16]. They who wear suit signifies success, seriousness, formality, and strict to the rules. It also means white middle-upper class patriarchal masculinity [16]. Derek wears casual clothes that imply freedom and personal comfort rather than formality and conformity, which implies contrasting masculinity. However, when Derek gets promoted to be the temporary Unit Chief of the BAU, he changes his clothes. Derek wears a shirt, which means he follows conformity and formality. He became a patriarch, but only if he could become superior.

The first season of Criminal Minds serves as an introduction to the FBI Behavioral Analysis Unit (BAU) and how the team works to investigate crimes. The first season revolves mostly around SSA Jason Gideon as the male lead character. Professional and personal problems of the team members have not arisen yet, including getting personally involved in the cases they investigate. However, the character SSA Derek Morgan gets highlighted in the second season when he was accused of killing young boys in his home, Chicago.

Criminal Minds Season 2 Episode 12 entitled Profiler Profiled centred on Derek, his family, and his childhood. Derek grew up in a neighbourhood in Chicago. His father was an African American, and his mother was Caucasian. In the beginning, it is shown that Derek always comes home to Chicago for his mother's birthday. Later on, it is shown that Derek was accompanying his sister, Desiree, doing some shopping. Then when they walked out of the shop into their car, they were confronted by a black man named Rodney Harris, who tried to harass Desiree. He protected his sister by ordering her to get in the car and blocked out Harris' way to reach Desiree. 
In this scene, it was apparent that there are two different representations of black masculinity. Black masculinity which showed by Derek and the one showed by Harris. Harris, who is described as a gangbanger, seemed to show the black masculinity defined by white patriarchal masculinity. He shows dominance over Derek. The dominance that Derek showed is by surrounding Derek with his gang members, indicating that he owns the street. He tries to dominate Morgan by mocking him, saying, "What, you think you a badass now because they pay you to wear that gun, Mr. FBI?" and "Bitch" in front of Morgan's face. Derek represents the reconstructed black masculinity that Hooks described, protecting his family without being dominated. The black masculinity Derek represented also include by keeping his calm and not using rant to counter Harris' dominance. Derek's act of protecting his sister without getting physical is what Hooks called as a benevolent patriarch. "Benevolent patriarchs exercise their power without using force" [14, p.3-4].

As the episode goes on, Derek and his sisters celebrate their mother's birthday. In this scene, the nuances are full of love and happiness. When his mother said that she lost her husband and she does not want to lose her son too, Derek assures her that she won't and holds his mother's hand tightly. This gesture reveals Derek's love for his mother. It is known that patriarchal standard to be masculine is men must hide their emotions, and Derek shows his love for his mother is the opposite of what patriarchal standard sets. It is in accordance with the story of Muhammad Ali that Hooks recounted in her book. Hooks [14] tells that "If patriarchal standards for manhood prized being silent and unemotional, Ali dared to ... express emotions... the image of Ali holding his mother, showing his love; everything a patriarchal man was not supposed to be and do." She also said that Ali represents the alternative masculine identity [14]. By showing his love to his family, especially his mother, it can be said that Derek's character is far from the depiction of conventional black masculinity. Instead, his act is similar to Ali's, which Hooks said represents the alternative black masculinity.

In a professional environment, Derek's relationship with his co-workers also exhibits his characteristics of a loving and caring black man. For example, Derek always calls one of his coworkers, Penelope Garcia by 'baby girl'. This call is not a flirt one rather an affectionate call. They also like to exchange compliments in a flirt way. Derek and Garcia's relationship are a platonic relationship. They are intimate and love one another but not engage in a sexual relationship. In season 3, episode 9, titled Penelope, Derek shows his fear, anxiety, and worry because Garcia was in a critical condition. Garcia was shot by a man she just met at the coffee shop. In the previous episode, we learn that Derek had warned her not to trust that man. He gave a warning not because of jealousy but because of love. After surgery, Garcia regained her consciousness and told Derek that she was stupid and did not take his advice seriously. Derek showed his disappointment and anger. By looking at his expression and gesture, it can be inferred that his love for Garcia is genuine as a brother to a sister.

Throughout his appearance on the series, Derek is seen as a ladies man because of his charming and attractive appearance. In the pilot episode, the series introduced Derek as he was surrounded by women in a bar and flirting with them. In season two, when part of the team hanging out in a bar, Derek was seen dancing with several women at one time. One of his coworkers, Garcia, commenting that by looking at the way he dances, Derek was not the one who was asking the women to dance, but it was the other way around. Derek is rather a ladies man than a playboy or a womanizer. It is because he does not engage in a committed relationship with more than one woman. He is only being good and respects to women around him. Womanizer is another portrayal of the desirable black masculinity concerning the romantic relationship in the African American community. As Hooks writes out, "in many African American communities the black man who womanizes, whose whole life is based on lies, 
secrets, and silences, is often seen as the epitome of desirable manhood" [14, p.121]. However, Derek is the opposite of that.

Eventually, as the series goes on, Derek got a girlfriend named Savannah Hayes, who is a doctor and later became his wife. Both are dedicated to their job, and it puts their relationship in many hard times. Being playboy and unfaithful are the stereotypes of black men. Hooks states that the romantic relationship between a black man and a black woman we usually hear is mostly negative ones, where the black man is seen as a playboy, and the black woman is seen as a whore, where there are cheating and violence [14, p.109)] "In popular culture, there are a bevy of loudmouths who let us know what goes wrong when black men and women get together" $[14$, p.109]. The abusive relationship between a black man and woman happens because to show his dominance over a black woman; a black man often uses violence:

"[black male] taught to believe that a real male is fearless, insensitive, egocentric, and invulnerable (all the traits powerful black men have in movies) a black man blocks out all emotions that interfere with this "cool" pose. Yet it is often in relationships with females, particular romantic bonds, that black males experience a disruption of the cool pose. They respond with anger and sexual predation to maintain their dominator stance." [14, p.57].

However, Derek's relationship with Savannah does not show that kind of feature. Otherwise, Derek shows loving, caring, and understanding character in his romantic relationship. Derek also shows his appreciation to Savannah by apologizing to her for did not make it to dinner and saying, "The next time you ask, I will not be late for you" (Derek, Season 11). Derek indicates what Hooks' goal for black men is to be a loving black male who loves himself and others [14]. His relationship with Savannah also confirms Derek's status as a man. Seeing Derek's treatment to Savannah promotes African American character to a new level of black masculinity that many African American men have not been able to reach on screen.

Derek is the only man in his family. Derek's father was a police officer. He was died from being shot in front of Derek when he was a kid. Being the only boy in the house, he got no one to look up to. After his father's death, he got himself to many problems that made him had juvenile records. Then he was taken under the wing of Carl Buford, the head of the community youth centre in his neighbourhood. Unfortunately, as a mentor and a role model for Derek, Buford let him down. Derek was one of Buford's favourite children in the youth centre, and he used his power to molest him. His past trauma becomes the motivation of Derek to become a police officer and catch bad guys like Buford. Derek's skill and persistence repeatedly help the team find the killers.

Derek's past event also led his anger comes out when the team got a case regarding children as victims. Derek was outraged and ambitious to find the suspect who sold and killed children. His motivation and action driven by his traumatic experience are seen in two episodes in season 2, P911 (2x02) and Boogeyman (2x06). It was also shown in one scene when all the clues and evidence point out to one suspect, Derek did not hesitate to take him down. Until his partner reminded him that he needed to take it easy because they need the suspect's cooperation to find the child. "Unlike women, male African American detective characters tend to be positioned according to stereotype as irrational-subjective. In this role, they are emotional and driven by hunches, sometimes even volatile and aggressive" [8, p.11-12]. However, Derek's aggressiveness in catching the suspect is not driven by hunches but by his traumatic event in the past. 


\section{Conclusion}

Using the approach of the clock of character, Derek Morgan as a fictional being shows that he has the characteristics of reconstructed black masculinity. He is loving, caring, benevolent, committed, and daring. Though he also shows stereotypes such as black men's aggressiveness, the motivation behind it is different. Hence, those characteristics symbolize him as the new kind of black masculinity. His character indicates the counter of black men's typical stereotypes. Derek's traits highlight the possibility of black masculinity in a police procedural drama. By looking at how black masculinity is positioned and shaped in a police procedural drama, we can infer that though the patriarchal structure is still maintained, black masculinity is given way to emerge. In some ways, Derek's growth presents a noteworthy portrayal of African American identity on television. Nevertheless, only within a police procedural crime action scenario can an African American break free of stereotypes. As Derek becomes a valuable member of the team, his reconstructed black masculinity is beneficial qualities for everyone. He is not just the black man in the tv series for diversity.

\section{References}

[1] CBS. About Criminal Minds. n.d. Retrieved from https://www.cbs.com/shows/criminal_minds/about/

[2] Legros EA. Unsubs and Profilers: Reality or Fiction? Depictions of Criminal Profiling in the Television Series "Criminal Minds". (Bachelors), Boston College, Boston, MA. 2010. Retrieved from http://hdl.handle.net/2345/1199

[3] Levin J. Representations of Victims, Suspects and Offenders: A Content Analysis of Four Television Crime Shows. University of Colorado Boulder, Boulder, CO. 2013.

[4] Bell GC, Harris TM. Exploring representations of Black masculinity and emasculation on NBC's Parenthood. Journal of International and Intercultural Communication. 2016;10(2):135-152. https://doi.org/10.1080/17513057.2016.1142598

[5] Tyree TCM, Byerly CM, Hamilton KA. Representations of (new) Black masculinity: A newsmaking case study. Journalism: Theory, Practice \& Criticism. 2011;13(4):467-482. https://doi.org/10.1177/1464884911421695

[6] Primasita FA, Ahimsa-Putra HS. An Introduction to the Police Procedural: A Subgenre of the Detective Genre. Humaniora. 2019;31(1):33-40. https://doi.org/10.22146/jh.v31i1.15309

[7] Harriss C. Policing Propp: Toward a Textualist Definition of the Procedural Drama. Journal of Film and Video. 2008;60(1):43-59. https://doi.org/10.1353/jfv.2008.0001

[8] Jenner M. American TV Detective Dramas: Serial Investigations. London, UK: Palgrave Macmillan; 2016. https://doi.org/10.1057/9781137425669

[9] Scharrer E. More Than "Just the Facts"?: Portrayals of Masculinity in Police and Detective Programs Over Time. Howard Journal of Communications. 2012;23(1):88-109. https://doi.org/10.1080/10646175.2012.641882

[10] Creeber G. Old Sleuth or New Man? Investigations into rape, murder and masculinity in Cracker (1993-1996). Continuum. 2002;16(2):169-183, https://doi.org/10.1080/10304310220138741

[11] Dixon TL, Linz D. Overrepresentation and underrepresentation of African Americans and Latinos as lawbreakers on television news. Journal of Communication 2000;50(2):131-154. https://doi.org/10.1111/j.1460-2466.2000.tb02845.x

[12] Dixon TL, Azocar CL. The Representation of Juvenile Offenders by Race on Los Angeles Area Television News. Howard Journal of Communications. 2006;17(2):143-161, https://doi.org/10.1080/10646170600656896

[13] Hooks B. Black Looks: Race and Representation. Boston, MA: South End Press; 1992.

[14] Hooks B. We Real Cool: Black Men and Masculinity. New York, NY: Routledge; 2004. 
[15] Eder J. Understanding Characters. Projections. 2010;4:16-40. https://doi.org/10.3167/proj.2010.040103.

[16] Barry B, Weiner N. Suited for Success? Suits, Status, and Hybrid Masculinity. Men and Masculinities. 2019;22(2):151-176. https://doi.org/10.1177/1097184X17696193 